Summary: We report herein calixarene derivatives, which could adapt to various fields of application, as novel pore generators for making nanoporous materials. The pore structure of nanoporous materials exhibits disordered pores with small mesopore diameter $(2-3 \mathrm{~nm})$, which is similar to the micelle-like assembled structure of the calixarene compounds. The electro-optical properties such as dielectric constants and refractive indexes of these porous thin films can easily be manipulated. The calixarene-templated nanoporous films could find a variety of potential applications, such as low-dielectric constant $(k)$ materials and high-surface area materials for catalysis and biotechnology.

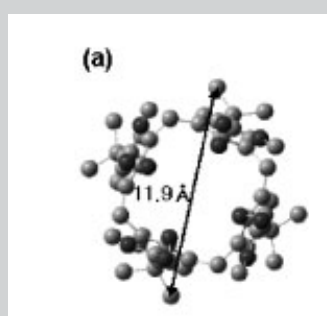

(c)

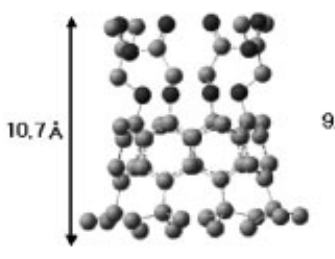

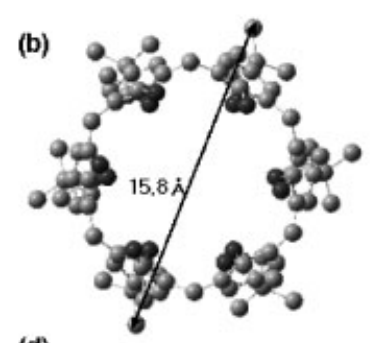

(d)

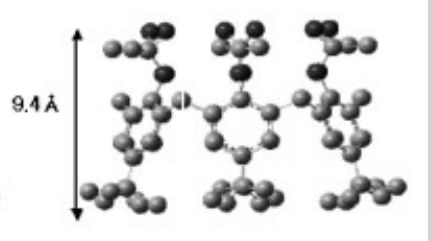

PM3-optimized structures of CA[4] and CA[6].

\title{
Calixarene Derivatives as Novel Nanopore Generators for Templates of Nanoporous Thin Films
}

\author{
Jin-Heong Yim, ${ }^{* 1}$ Jongseob Kim, ${ }^{2}$ David. W. Gidley, ${ }^{3}$ Richard S. Vallery, ${ }^{3}$ Hua-Gen Peng, ${ }^{3}$ Duk Keun An, ${ }^{4}$ \\ Byoung-Ki Choi, ${ }^{5}$ Young-Kwon Park, ${ }^{6}$ Jong-Ki Jeon $^{7}$ \\ ${ }^{1}$ Division of Advanced Materials Engineering, Kongju National University, 182, Sinkwan-dong, Gongju City, \\ Chungnam 314-701, Korea \\ E-mail: jhyim@kongju.ac.kr \\ ${ }^{2}$ CSE Center, Samsung Advanced Institute of Technology (SAIT), San 14-1, Nongseo-ri, Kiheung-eup, \\ Yongin-si, Kyungki-do 449-712, Korea \\ ${ }^{3}$ Department of Physics, University of Michigan, Ann Arbor, Michigan 48109, USA \\ ${ }^{4}$ Department of Chemistry, Kangwon National University, Chun-Chon 200-701, Korea \\ ${ }^{5}$ Flex. Display Program Team, Samsung Advanced Institute of Technology (SAIT), San 14-1, Nongseo-ri, \\ Kiheung-eup, Yongin-si, Kyungki-do 449-712, Korea \\ ${ }^{6}$ Faculty of Environmental Engineering, University of Seoul, 90 Jeonnong-dong, Dongdaemun-gu, Seoul 130-743, Korea \\ ${ }^{7}$ Department of Chemical Engineering, Kongju National University, Gongju 314-701, Korea
}

Received: November 3, 2005; Revised: January 17, 2006; Accepted: January 17, 2006; DOI: 10.1002/mame.200500370

Keywords: dielectric properties; polysiloxanes; self-organization; surfactants; thin films

\section{Introduction}

Porous materials with ordered micropores (typically less than $2 \mathrm{~nm}$ ) have been used widely as catalysts, adsorbents, and as various supporting materials. ${ }^{[1]}$ Extensive research has been performed in the syntheses of new porous materials with the goal of extending the pore diameter to the mesoporous region (typically $2-50 \mathrm{~nm}$ ). ${ }^{[2-5]}$ Control of pore size and pore size distribution of such porous materials is possible utilizing different types of pore templates and manipulation of synthesis parameters, such as the porogen concentration, processing temperature, and drying 
conditions. Mesoporous thin films can be simply prepared using a spin-on composite containing a thermally stable precursor together with a pore generator (porogen), which is then decomposed and volatilized at elevated temperature leaving pores in the film. Several varieties of porogens have been introduced to control the pore structure in the films. ${ }^{[5-17]}$ It has been introduced the potentials to use cyclodextrin $(\mathrm{CD})$ derivatives as a porogen. CD-based porogens have the attractive properties ${ }^{[16]}$ of a narrow thermal decomposition window, well-defined three-dimensional (3-D) molecular size $(<2 \mathrm{~nm})$, and few residual components after decomposition. Moreover, the mutual interaction between porogen molecules and between porogen and matrix molecules may be engineered to control nanocomposite domain structure (and hence the resulting pore structure) by changing the functional end groups of the CD molecule. ${ }^{[17]}$

The calixarene (CA) derivatives, a well-known cyclic "supramolecule" compound, are currently the most extensively studied molecular capsule because they show a structure similar to that of CD compounds. ${ }^{[18-20]}$ The range of maximum diameters of the $\mathrm{CA}$ derivatives depends on the number of repeating arene units (typically 4,6 , or 8 ) and is $1.2-2.0 \mathrm{~nm}$. Therefore, we believe that CA derivatives show promise as a nanopore template for making porous materials. This article introduces $\mathrm{CA}$ as a pore template material for producing porous thin films. In order to understand the decomposition behaviors of $\mathrm{CA}$ and confirm its potential as a porogenic material, FT-IR studies were preformed. Pore sizes, distributions, and porosity of the porous thin films were investigated by means of positronium annihilation lifetime spectroscopy (PALS), ellipsometric porosimetry (EP), and transmission electron microscopy (TEM). We have also monitored the variation of refractive index, electrical properties, and mechanical properties of the porous thin films produces using CA derivatives in order to evaluate their applicability to low- $k$ dielectric.

\section{Experimental Part}

\section{Materials and Synthesis of the SSQ-Based Precursor and CA[6]}

4-tert-Butyl calix[4] arene- $O, O^{\prime}, O^{\prime \prime}, O^{\prime \prime \prime}$-tetraacetic acid tetraethyl ester (CA[4]), 4-tert-butylcalix[6]arene, and acetic anhydride (all from Aldrich Chemical Co.) were used as received without further purification.

Recently, a novel silsesquioxane (SSQ)-based precursor has been developed as a matrix material having excellent mechanical properties. ${ }^{[21,22]}$ The $\mathrm{Si}-\mathrm{OH}$ content of the SSQ precursor calculated by ${ }^{1} \mathrm{H}$ NMR (Bruker AM300) was $32.2 \mathrm{~mol}-\%$, and the weight-average molecular weight $\left(\bar{M}_{\mathrm{w}}\right)$ and polydispersity measured by gel permeation chromatography (Waters 2690) were 2930 and 2.14, respectively. The 5,11,17,23,29,35-hexa-tert-butyl-37,38,39,40,41, 42-hexa-acetoxyl calix[6]arene (CA[6]) was synthesized as follows: $3.0 \mathrm{~g}(3.09 \mathrm{mmol})$ of 4-tert-butylcalix[6]arene was dissolved in $90 \mathrm{ml}$ of $\mathrm{Ac}_{2} \mathrm{O}$, treated with three drops of conc. $\mathrm{H}_{2} \mathrm{SO}_{4}$, and refluxed for $3 \mathrm{~h}$. The reaction mixture was cooled to room temperature, poured into ice water, and then extracted with $\mathrm{CHCl}_{3}$. The organic layer was washed with brine, dried over anhydrous $\mathrm{Na}_{2} \mathrm{SO}_{4}$, filtered, and concentrated under reduced pressure. The acetoxyl calix[6]arene was purified by column chromatography on silica gel. The structure of CA[6] compound was confirmed by comparison of the ${ }^{1} \mathrm{H}$ NMR and IR of the same molecule with the reported one. ${ }^{[18]}$

\section{Molecular Modeling of Calixarene Derivatives}

Molecular structures of $\mathrm{CA}[4]$ and $\mathrm{CA}[6]$ are optimized by $\mathrm{PM}^{[23]}$ semi-empirical quantum mechanical calculation using Gaussian 98 program suite. ${ }^{[24]}$ For CA[4] and CA[6], there are several stable conformers and the energy differences among them are quite small. In the case of CA[4], four different conformations are possible and the energy differences among them are within $1 \mathrm{kcal} \cdot \mathrm{mol}^{-1}$. To optimize the structures shown in Figure 1, we assume the rotational point group symmetry, i.e., $C_{4}$ symmetry for $\mathrm{CA}[4]$ and $C_{6}$ symmetry for $\mathrm{CA}[6]$.

\section{Preparations and Characterizations of Porous Thin Films}

The spin-on coating solutions were prepared by properly mixing the SSQ precursor as a matrix with CA compounds as a porogen and propylene glycol methyl ether acetate (PGMEA) as a solvent. The porous films were prepared in accordance with our previous paper. ${ }^{[17]}$

IR spectra of the precursor were recorded by FT-IR (BOMEM MB-104) with in situ heating cell under $\mathrm{N}_{2}$ atmosphere. Refractive index and thickness of thin films were measured by prism coupler (Metricon Co., Prism coupler 2010). The film porosity, pore radius distribution (PRD), and porosity were analyzed by EP. ${ }^{[25]}$ A more detailed description of the method can be found elsewhere. ${ }^{[2-27]}$ The morphology of porous films was investigated by TEM (Hitachi H9000NA) at $300 \mathrm{kV}$ for the electron transparent cross-section specimens which were prepared by argon ion beam milling technique. Depth-profiled PALS was used to determine the pore size and pore interconnectivity in these thin films. The details of the instrumental setup and measurement methods appear elsewhere. ${ }^{[28,29]}$ The positronium (Ps) lifetime can be correlated with pore size using the extended Tao-Eldrup model. ${ }^{[30]}$ The dielectric constant of each film with MIM (metal-insulator-metal) structure was measured by LCR meter (HP 4284) instrument at a frequency of $100 \mathrm{kHz}$. The hardness $(H)$ and elastic modulus $(E)$ of the thin films were measured using the continuous stiffness measurement (CSM) nanoindentation method. ${ }^{[31]}$

\section{Results and Discussion}

The polar organic solvents such as butanol, methyl isobutyl ketone (MIBK), and PGMEA, etc. have been used for a spin coating of SSQ-based material. In this study, two kinds of 
(a)

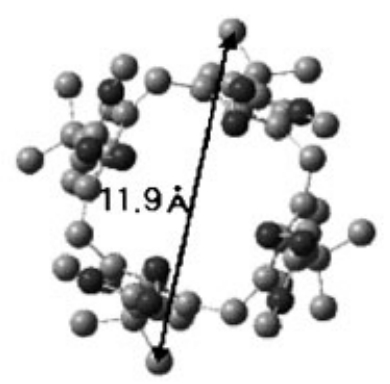

(c)

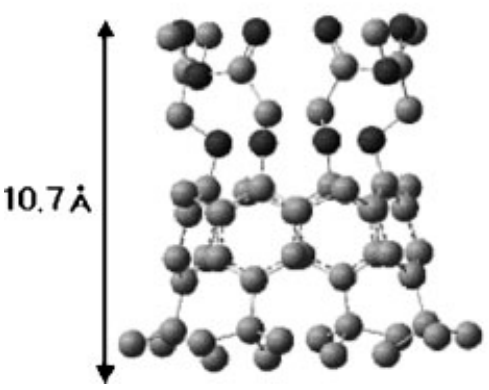

(b)

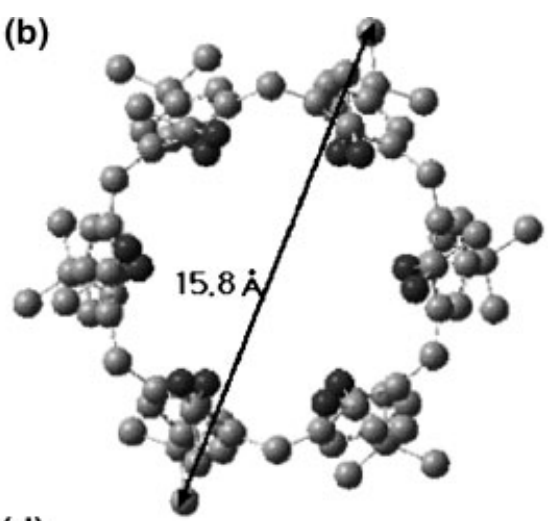

(d)

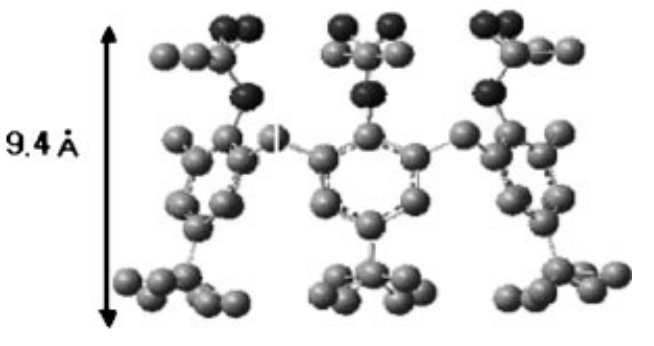

Figure 1. PM3-optimized structures of CA[4] and CA[6]. (a) the front view of CA[4], (b) the front view of CA[6], (c) the side view of CA[4], and (d) the side view of CA[6]. Dark gray spheres represent oxygen atoms, and gray spheres denote carbon atoms.

CA compounds that have good solubility in the polar organic solvents were used to make CA-templated porous thin films. The first CA compound is a four-membered arene ring having alkoxy ester groups, $\mathrm{CA}[4]$, while the second is a six-membered arene ring having acetoxyl groups, $\mathrm{CA}[6]$ (see Figure 1). According to the molecular modeling based on the semi-empirical quantum mechanic theory (PM3), the maximum diameter of $\mathrm{CA}[4]$ and $\mathrm{CA}[6]$ is about 1.20 and $1.60 \mathrm{~nm}$, respectively. As shown in Figure 1, the aspect ratios of CA[4] with alkoxy ester groups and $\mathrm{CA}[6]$ with acetoxyl groups are different. Even though the diameter of $\mathrm{CA}[4]$ is shorter than $\mathrm{CA}[6]$, the height of $\mathrm{CA}[4]$ is larger because of the differences in side chain group. CA[4] appears to have a cylindrical shape while $\mathrm{CA}[6]$ is a truncated cone. The molecular structure of the CA compounds seems to be similar to previously studied CD systems, ${ }^{[16,17]}$ which has 3 -D cyclic supramolecule as shown in Figure 1. In terms of the molecular interaction, however, the CA derivatives are completely different from the CD derivatives. Like conventional surfactant molecules, usually used in self-assembly template for making an ordered mesoporous structure, the upper plane of the $\mathrm{CA}$ [4] and $\mathrm{CA}[6]$ compounds are hydrophilic while the bottom plane is hydrophobic. Thus, only the upper plane can make hydrogen bonds with hydroxyl groups from the SSQ matrix, whereas in case of $\mathrm{CD}$ both the upper and lower planes can make hydrogen bonds with a SSQ matrix. In other words, the CA compound may act as supramolecular surfactant in the SSQ precursor solution. Moreover in the case of CD molecules, there are strong electrostatic interactions between hydrophilic planes of CDs, which affects the agglomeration of $\mathrm{CD}$ molecules and pore collapse during the matrix vitrification. ${ }^{[32]}$ Thus, we can expect the yield of porosity to be more efficient when we use the same content of $\mathrm{CA}$ as a porogen instead of $\mathrm{CD}$ in the coating precursor.

In order to understand the structural changes of $\mathrm{CA}$ and thin films made from a mixture of SSQ and CA as a function of temperature, FT-IR spectra were collected at increasing temperature (see Figure 2). The characteristic peak in the CA molecules is a carbonyl group $(\mathrm{C}=\mathrm{O})$ peak located at $1718 \mathrm{~cm}^{-1}$. This peak remains up to $250^{\circ} \mathrm{C}$, indicating that the 3-D structure of CA molecules can sustain up to $250{ }^{\circ} \mathrm{C}$ before being decomposed at higher temperatures. Hydroxyl groups such as $-\mathrm{OH}$ and $\mathrm{Si}-\mathrm{OH}$ are found at 3400 and $910 \mathrm{~cm}^{-1}$, respectively, and mainly emerge from the SSQbased precursor. The height of these peaks decreases as a function of temperature due to polycondensation reactions between the precursor molecules. It seems that the polycondensation is partially completed up to $250^{\circ} \mathrm{C}$. Therefore, the CA compounds can be used as a porogen material because its 3-D structure can be sustained while the SSQ matrix vitrifies.

It is difficult to detect the pores that exist in the SSQ/ CA[4] films by means of TEM. No clear pore structure is 

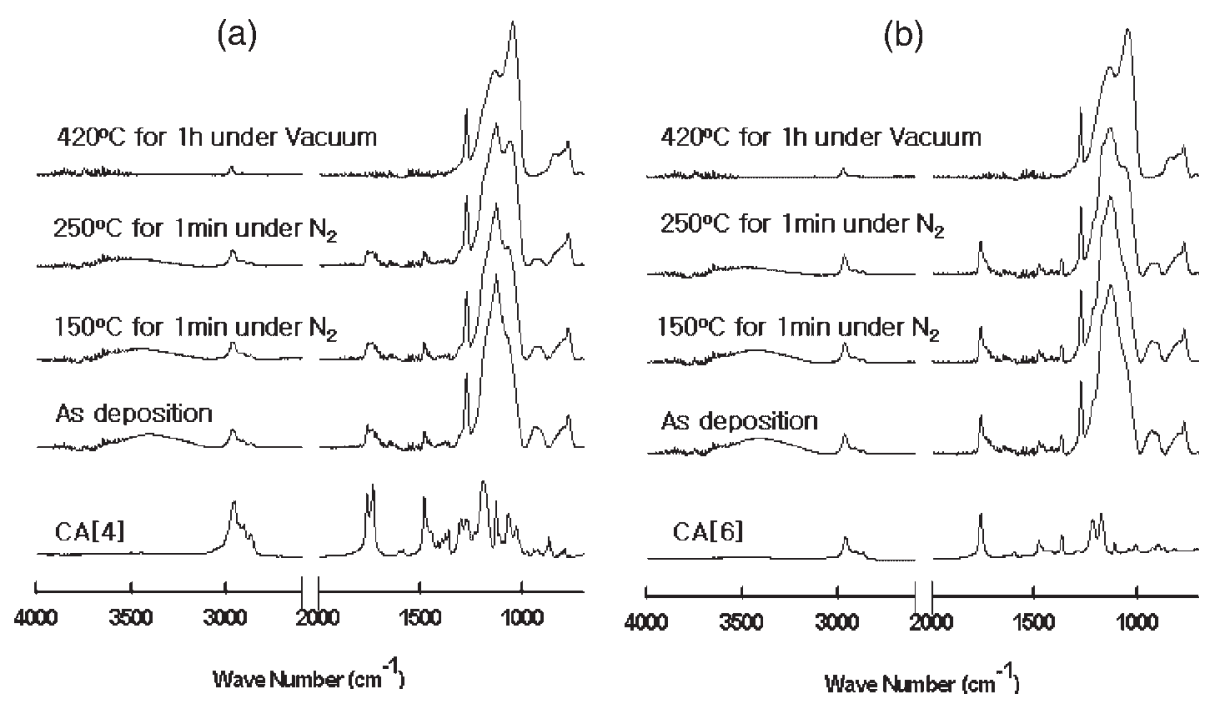

Figure 2. Temperature sweep in situ FT-IR spectra of (a) SSQ/CA[4] mixture (content of $\mathrm{CA}[4]=30 \mathrm{wt} .-\%$ ) and (b) SSQ/CA[6] mixture (content of $\mathrm{CA}[4]=30 \mathrm{wt} .-\%$ ).

detected in the porous thin films made from the mixture of SSQ and CA[4] with 10 and 30 wt.-\%, as shown in Figure 3. The TEM results indicate that there is no detectable severe agglomeration of CA molecules, which would result in morphological defects in the siloxane films, and the nanopores in the thin films are distributed homogeneously. The morphology of the film made from SSQ/CA[4] 10 wt.$\%$ is similar to that of SSQ alone. In the case of SSQ/CA[6] 30 wt. $\%$, however, the morphology seems to be much coarser than that of SSQ/CA[4] 10 wt.-\%, which might be attributed to larger pores in the film.

Measurements of the refractive index decrease, as expected, as the porosity effectively increases as a function of weight content of CA[4] and CA[6], as shown in Table 1. The porosities of thin films are calculated from the LorentzLorentz equation as shown in the footnote of Table 1. The deduced porosity of the thin films is approximately linear in the weight content of CA compounds used in the coating mixtures, which is a strong indication that there is no significant pore collapse during decomposition of CAbased porogens.

Measurements of the pore sizes and pore interconnection lengths are done using the Michigan beam-based PALS spectrometer. This technique has been extensively used to study nanoporous materials and is discussed elsewhere (see Experimental Part). All the PALS spectra from these films present two short Ps lifetimes corresponding to the micropores inherent to the SSQ matrix (see Table 1). In the CA[4] series of increasing weight fraction the porogeninduced pores produce one additional intermediate lifetime, $\tau_{\text {meso }}$, corresponding to pore diameters ranging from $1.2 \mathrm{~nm}$ to about $2.8 \mathrm{~nm}$. With increasing porosity, the intensity of the longest Ps lifetime component $(\approx 140 \mathrm{~ns}$, consistent with the lifetime of Ps in vacuum) systematically increases. This indicates that Ps is increasingly escaping into vacuum through pores with some degree of interconnection, as shown in
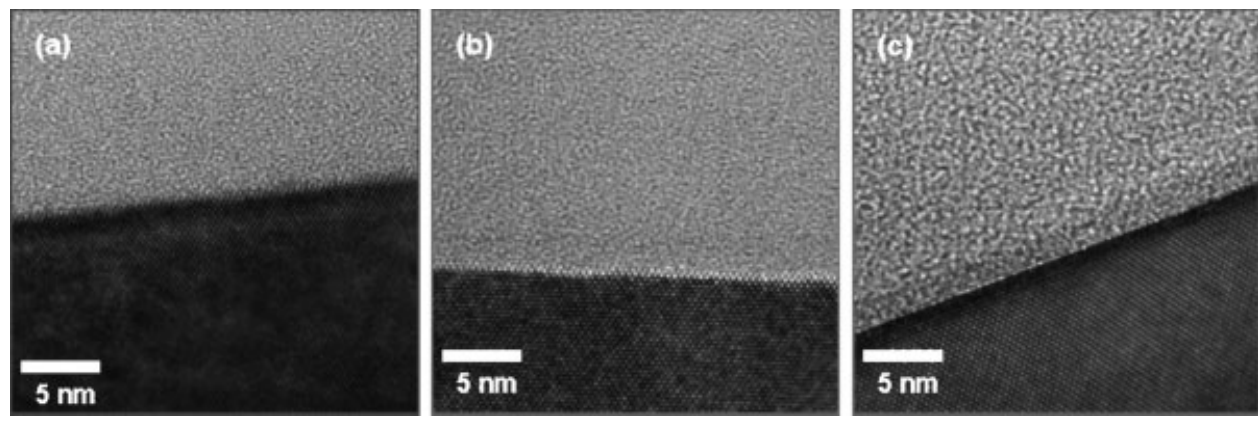

Figure 3. Transmission electron microscope images of (a) SSQ, (b) SSQ/CA[4] 10 wt.-\%, and (c) SSQ/CA[4] $30 \mathrm{wt} .-\%$. 
Table 1. The summary of nanopore structure of the porous film made with the mixture of SSQ precursor and two kinds of CA compounds.

\begin{tabular}{|c|c|c|c|c|c|}
\hline \multirow[t]{2}{*}{ Sample } & \multirow[t]{2}{*}{ R. I. ${ }^{a)}$} & Porosity $^{b)}$ & \multirow{2}{*}{$\frac{\tau_{\text {meso }}^{\mathrm{c})}}{\mathrm{ns}}$} & \multirow{2}{*}{$\frac{\text { Size }^{\mathrm{c})}}{\mathrm{nm}}$} & \multirow{2}{*}{$\frac{L_{\text {Inter }}^{\mathrm{c})}}{\mathrm{nm}}$} \\
\hline & & $\%$ & & & \\
\hline SSQ & 1.3856 & - & 0.0 & $0.60,1.10$ & 0 \\
\hline $\mathrm{SSQ} / \mathrm{CA}[4] 10 \%$ & 1.3586 & 6.28 & 12.5 & 1.24 & 30 \\
\hline $\mathrm{SSQ} / \mathrm{CA}[4] 20 \%$ & 1.2986 & 20.65 & 33.8 & 2.07 & 185 \\
\hline $\mathrm{SSQ} / \mathrm{CA}[4] 30 \%$ & 1.2555 & 31.33 & 43.6 & 2.46 & $400-450$ \\
\hline $\mathrm{SSQ} / \mathrm{CA}[4] 40 \%$ & 1.2139 & 41.90 & 50.6 & 2.79 & $>550$ \\
\hline SSQ/CA[6] $10 \%$ & 1.3577 & 6.49 & 12.5 & 1.24 & $<5$ \\
\hline $\mathrm{SSQ} / \mathrm{CA}[6] 20 \%$ & 1.3235 & 14.70 & 27,65 & $1.8,3.6$ & 400 \\
\hline SSQ/CA[6] 30\% & 1.2678 & 28.34 & n.m. & n.m. & Interconnected \\
\hline $\mathrm{SSQ} / \mathrm{CA}[6] 40 \%$ & 1.2239 & 39.40 & n.m. & n.m. & Interconnected \\
\hline
\end{tabular}

a) Refractive index was measured by Prism Coupler.

b) Porosity is calculated by Lorentz-Lorentz equation.

c) Pore size and interconnection length were measured by PALS (value was derived by cylinder model from MFP).

Table 1. PALS fitting of the CA[6] series is more complicated. The 10 wt.- $\%$ loaded film is as straightforward as the CA[4] 10 wt.-\% film, but for the higher porosity films the porogeninduced pores require at least two intermediate mesopore lifetimes. The 20 wt.-\% loaded CA[6] film presents two wellresolved pore diameters of $1.8 \mathrm{~nm}$ and another of $\approx 3.6 \mathrm{~nm}$. The 30 and $40 \mathrm{wt}$. $\%$ films present similar-sized pores, but also include even larger pores that are virtually un-resolved from the vacuum lifetime, suggesting diameters $\geq 20 \mathrm{~nm}$. These large pores are highly interconnected into a network, but the smaller pores may be relatively isolated from this large network. Overall, the PALS results indicate robust increase in pore diameter with porosity for the $\mathrm{CA}[4]$ case and almost explosive pore growth in the case of CA[6]. The 10 wt.- $\%$ loaded films have mesopores nominally consistent with the individual CA-based porogen molecule (see Figure 1), but increased porogen content apparently leads to rapid porogen assemble and form micelle-like CA porogen domain (2.5-3.0 $\mathrm{nm}$ ) in the case of CA[4]. However the CA[6] system, which has a greater number of hydrophilic function groups, tends to undergo severe aggregation and concomitant pore interconnection beyond $30 \mathrm{wt} .-\%$ porogen loading.

These CA systems show the interconnection tendency resulting from cylindrical stacks of CA molecules (1-D linear growth) even though relatively low content of CAbased porogen $(<10 \mathrm{wt} .-\%)$ is used as described in Table 1. The interconnection length of the $10 \mathrm{wt} .-\%$ CA-templated porous films is $5-30 \mathrm{~nm}$, which means partially interconnected. A critical transition of pore structure may occur from the 20 wt.-\% CA-based porogen. It seems that the formation of 3-D cylindrical micelles appears a very likely interpretation for the sudden onset of such large $(2-4 \mathrm{~nm})$ and interconnected (interconnection length: $185 \mathrm{~nm}$ approximately fully interconnected) pores.

Figure 4 shows the results of EP evaluation of these films. Adsorption-desorption isotherms in the films prepared with $\mathrm{CA}[4]$ porogen are typical of those for mesoporous films that is a slight hysteresis loop between the adsorption and desorption branches exists. The slopes correspond to average pore diameter in the range of $2-3 \mathrm{~nm}$ as well as small micropores. These artificial mesopores $(2-3 \mathrm{~nm})$ should come from the domain of assembled CA[4] porogens. However, the CA[6]-based SSQ film shows multimodal PRD. The CA[6] 30 wt.-\% templated film contains internal voids with diameters 3.6 and $12.7 \mathrm{~nm}$ (desorption branch), owing to micelle-like CA[6] domain and explosively agglomerated CA[6] molecules, respectively. Quantitative pore analysis results of EP are consistent with that of PALS measurements.

In order to understand the relationship between the pore structure and film properties, we monitored dielectric constant, modulus, and hardness of porous SSQ thin films having different pore structure as summarized in Table 2. Figure 5 shows elastic modulus of various SSQ-based thin films as a function of density ratio. Mechanical properties of the films exponentially decrease with increasing porosity [Figure 5(a)]. In general, dielectric constant decreases linearly as increasing the films porosity; however, the mechanical property decreases exponentially. It means that the mechanical properties depend on the porosity as well as pore structure. The behaviors of elastic modulus of SSQ/CA system is well described with the power-law equation, ${ }^{[33]}$ given in the legend of Figure 5(a). According to Jain et al., the power-law exponent can be less than 2 for closed-cell foams. ${ }^{[33]}$ The pore structure of CA-templated films seems to be an open-cell foam because the exponent of the powerlaw equation is 2.44. This result is also consistent with PALS experimental results. The change of the dielectric constant with density/porosity deviates from the ClausiusMossotti (C-M) equation, which suggests that the skeletal density of the matrix material does not change with the introduction of porosity [Figure 5(b)]. These results are an indication that pore wall density variation may have occurred in the SSQ/CA system. 

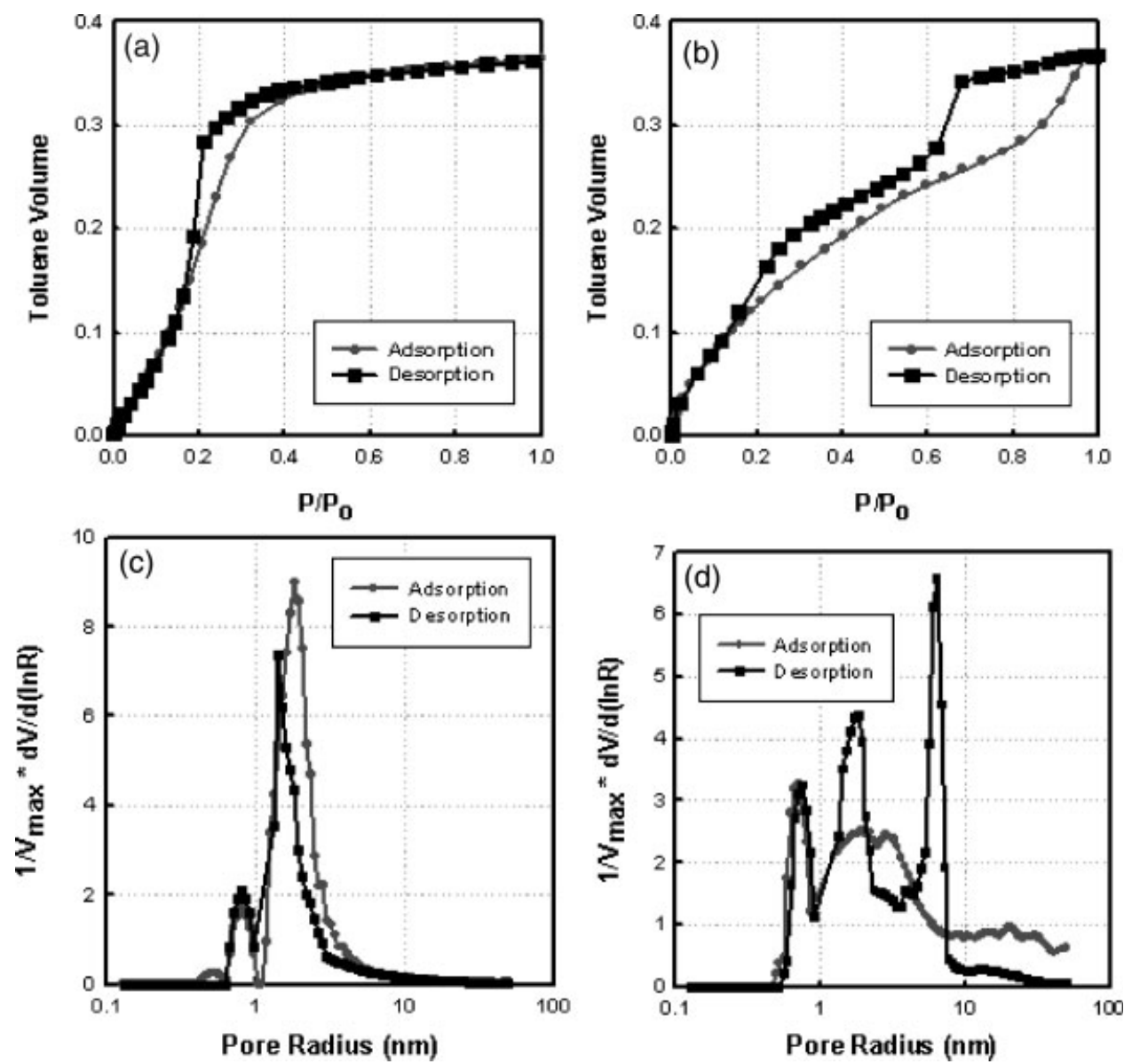

Figure 4. Typical isotherm for (a) SSQ/CA[4] $30 \mathrm{wt.} \%$ and (b) SSQ/CA[6] $30 \mathrm{wt} .-\%$, and PRD curve for (c) SSQ/CA[4] $30 \mathrm{wt.}$ \% $\%$ and (d) SSQ/CA[6] $30 \mathrm{wt} .-\%$ of the porous thin film by means of EP.

Table 2. The electrical and mechanical property of porous thin films prepared with SSQ precursor and various contents of two kinds of CA compounds.

\begin{tabular}{|c|c|c|c|c|c|}
\hline \multirow[t]{3}{*}{ Sample } & \multirow{3}{*}{$\begin{array}{c}\text { Thickness } \\
\mathrm{nm}\end{array}$} & \multicolumn{2}{|c|}{ Mechanical property } & \multicolumn{2}{|c|}{ Electrical property } \\
\hline & & \multirow{2}{*}{$\frac{\text { Hardness }^{\text {a) }}}{\mathrm{GPa}}$} & \multirow{2}{*}{$\begin{array}{c}\text { Modulus }^{\mathrm{a})} \\
\mathrm{GPa}\end{array}$} & \multirow{2}{*}{$\begin{array}{c}\text { Dielectric } \\
\text { constant }^{\text {b) }} \\
k\end{array}$} & \multirow{2}{*}{$\begin{array}{l}\text { Dissipation } \\
\text { factor }^{b)}\end{array}$} \\
\hline & & & & & \\
\hline SSQ & 1421 & 9.11 & 1.45 & 3.04 & 0.004 \\
\hline $\mathrm{SSQ} / \mathrm{CA}[4] 10 \%$ & 1315 & 7.51 & 1.23 & 2.72 & 0.003 \\
\hline $\mathrm{SSQ} / \mathrm{CA}[4] 20 \%$ & 1379 & 5.24 & 0.86 & 2.10 & 0.002 \\
\hline $\mathrm{SSQ} / \mathrm{CA}[4] 30 \%$ & 1502 & 3.14 & 0.51 & 1.93 & 0.003 \\
\hline $\mathrm{SSQ} / \mathrm{CA}[4] 40 \%$ & 1363 & 2.88 & 0.46 & 1.88 & 0.002 \\
\hline $\mathrm{SSQ} / \mathrm{CA}[4] 50 \%$ & 1139 & 2.10 & 0.40 & 1.59 & 0.003 \\
\hline SSQ/CA[6] $10 \%$ & 1378 & 7.63 & 1.23 & 2.80 & 0.001 \\
\hline SSQ/CA[6] $20 \%$ & 1321 & 4.21 & 0.62 & 2.41 & 0.003 \\
\hline $\mathrm{SSQ} / \mathrm{CA}[6] 30 \%$ & 1336 & 2.81 & 0.40 & 2.06 & 0.002 \\
\hline $\mathrm{SSQ} / \mathrm{CA}[6] 40 \%$ & 1352 & 1.73 & 0.26 & 1.79 & 0.004 \\
\hline SSQ/CA[6] 50\% & 1116 & 1.49 & 0.13 & 1.49 & 0.001 \\
\hline
\end{tabular}



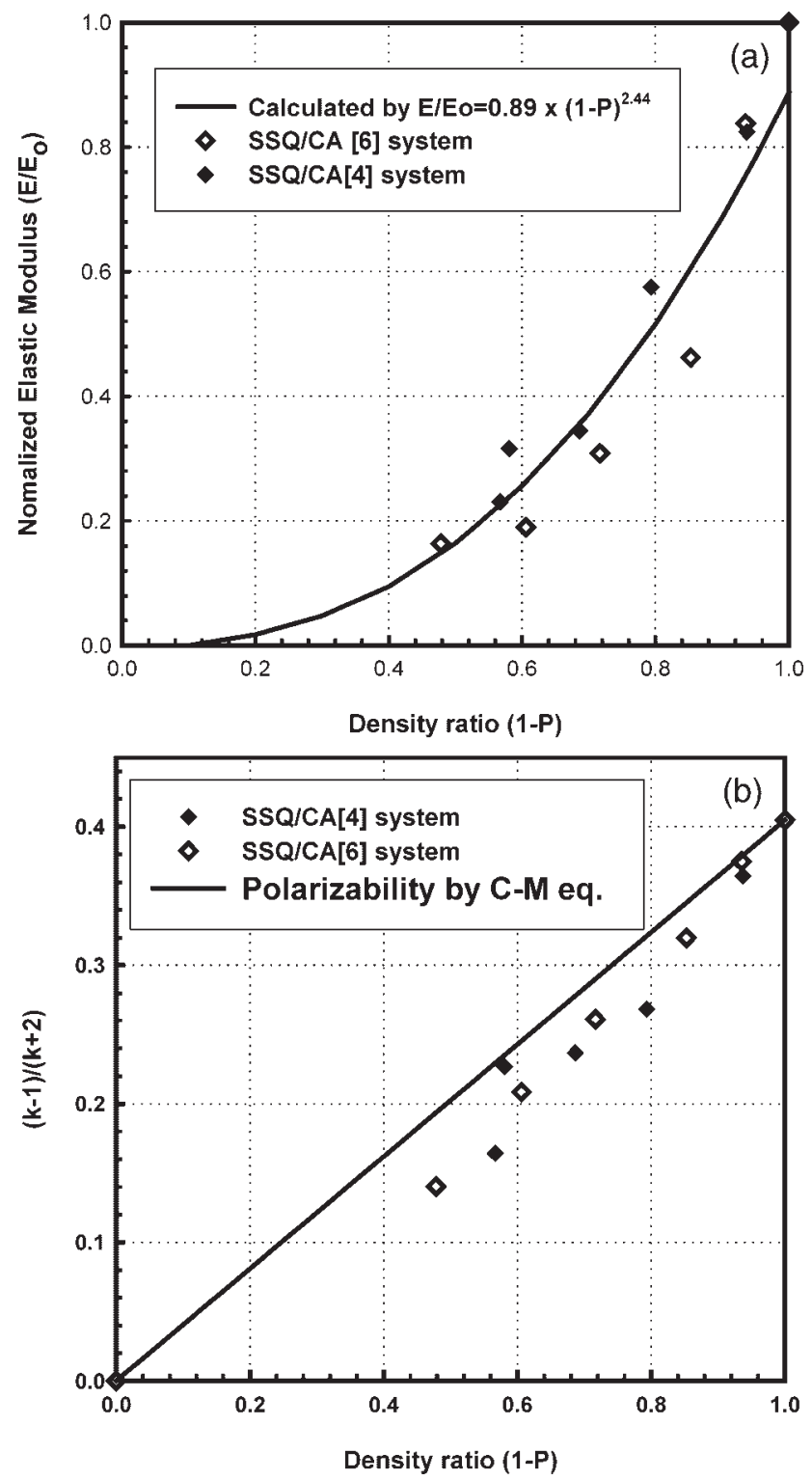

Figure 5. (a) Variation of mechanical property and (b) variation of polarizability of porous SSQ thin films as a function of density ratio.

\section{Conclusion}

As far as we know, this is the first time that CA derivatives, which could be adapted to various applications, are used as pore generators for making nanoporous materials. The pore structure of the nanoporous materials using the CA-based supramolecule porogen shows partially interconnected disordered pores with mesopore diameters in the range of $2-3 \mathrm{~nm}$, which is similar to the dimension of 3-D assembled micelles, and which consists of the calix[4]arene-based supramolecule porogen. The dielectric constants $(k=3.0-$ $1.5)$ and refractive indexes $(1.38-1.20)$ of these porous thin films can be easily tuned by controlling the amount of porogen loading.
Acknowledgements: The authors are grateful to Samsung Advanced Institute of Technology and Kongju National University for their financial support.

[1] A. Corma, Chem. Rev. 1997, 97, 2373.

[2] C. T. Kresge, M. E. Leonowicz, W. J. Roth, J. C. Vartuli, J. S. Beck, Nature 1992, 359, 710.

[3] T. Yanagisawa, T. Shimizu, K. Kuroda, C. Kato, Bull. Chem. Soc. Jpn. 1990, 63, 988.

[4] R. Tamaki, Y. Chujo, J. Mater. Chem. 1998, 8, 1113.

[5] B. Lee, Y.-H. Park, Y.-T. Hwang, W. Oh, J. Yoon, M. Ree, Nature Mat. 2005, 4, 147.

[6] H. C. Kim, J. B. Wilds, C. R. Kreller, W. Volksen, P. J. Brock, V. Y. Lee, T. Magbitang, J. L. Hedrick, C. J. Hawker, R. D. Miller, Adv. Mater. 2002, 14, 1637.

[7] J. L. Hedrick, R. D. Miller, C. J. Hawker, K. R. Carter, W. Volksen, D. Y. Yoon, M. Trollsas, Adv. Mater. 1998, 10, 1049.

[8] C. V. Nguyen, K. R. Carter, C. J. Hawker, J. L. Hedrick, R. L. Jaffe, R. D. Miller, J. F. Remenar, H. W. Rhee, P. M. Rice, M. F. Toney, M. Trollsas, D. Y. Yoon, Chem. Mater. 1999, 11, 3080.

[9] A. T. Kohl, R. Mimna, R. Shick, L. Rhodes, Z. L. Wang, P. A. Kohl, Electrochem. Solid-State Lett. 1999, 2, 77.

[10] F. J. deTheije, A. R. Balkenendl, M. A. Verheijen, M. R. Baklanov, K. P. Mogilnikov, Y. Furukawa, J. Phys. Chem. B. 2003, 107, 4280.

[11] S. Yang, P. A. Mirau, C. Pai, O. Nalamasu, E. Reichmanis, J. C. Pai, Y. S. Obeng, J. Seputro, E. K. Lin, H. Lee, J. Sun, D. W. Gidley, Chem. Mater. 2002, 14, 369.

[12] B. Lee, W. Oh, Y. Hwang, Y.-H. Park, J. Yoon, K. S. Jin, K. Heo, J. Kim, K.-W. Kim, M. Ree, Adv. Mater. 2005, 17, 696.

[13] B. Lee, W. Oh, J. Yoon, Y. Hwang, J. Kim, B. G. Landes, J. P. Quintana, M. Ree, Macromolecules 2005, 38, 8991.

[14] J.-S. Kim, H.-C. Kim, B. Lee, M. Ree, Polymer 2005, 46, 7394.

[15] J.-H. Yim, H.-D. Jeong, Y. S. Pu, Thin Solid Films 2005, 476, 46.

[16] J.-H. Yim, Y.-Y. Lyu, H.-D. Jeong, S. A. Song, I.-S. Hwang, J. Hyeon-Lee, S. K. Mah, S. Chang, J.-G. Park, Y. F. Hu, J. N. Sun, D. W. Gidley, Adv. Func. Mater. 2003, 13, 382.

[17] J.-H. Yim, J.-B. Seon, H.-D. Jeong, Y. S. Pu, M. R. Baklanov, D. W. Gidley, Adv. Func. Mater. 2004, 14, 277.

[18] C. D. Gutsche, B. Dhawan, K. H. No, R. Muthukrishnan, J. Am. Chem. Soc. 1981, 103, 3782.

[19] Y. L. Cho, D. M. Rudkevich, J. Rebek, Jr., J. Am. Chem. Soc. 2000, 122, 9868 .

[20] S. D. Alexandratos, S. Natesan, Macromolecules 2001, 34, 206.

[21] J.-H. Yim, Y.-Y. Lyu, H.-D. Jeong, S. K. Mah, J. Hyeon-Lee, J.-H. Hahn, G. S. Kim, S. Chang, J.-G. Park, J. Appl. Polym. Sci. 2003, 90, 626

[22] Y.-Y. Lyu, J.-H. Yim, Y. Byun, S.-Y. Lee, I.-S. Jung, L. S. Pu, Eur. Polymer. J. 2004, 40, 2505.

[23] J. J. P. Stewart, J. Comput. Chem. 1989, 10, 209.

[24] M. J. Frisch, G. W. Trucks, H. B. Schlegel, G. E. Scuseria, M. A. Robb, J. R. Cheeseman, V. G. Zakrzewski, J. A. Montgomery, Jr., R. E. Stratmann, J. C. Burant, S. Dapprich, J. M. Millam, A. D. Daniels, K. N. Kudin, M. C. Strain, O. Farkas, J. Tomasi, V. Barone, M. Cossi, R. Cammi, B. Mennucci, C. Pomelli, C. Adamo, S. Clifford, J. Ochterski, G. A. Petersson, P. Y. Ayala, Q. Cui, K. Morokuma, D. K. Malick, A. D. Rabuck, K. Raghavachari, J. B. Foresman, J. Cioslowski, J. V. Ortiz, A. G. Baboul, B. B. Stefanov, G. Liu, 
A. Liashenko, P. Piskorz, I. Komaromi, R. Gomperts, R. L. Martin, D. J. Fox, T. Keith, M. A. Al-Laham, C. Y. Peng, A. Nanayakkara, M. Challacombe, P. M. W. Gill, B. Johnson, W. Chen, M. W. Wong, J. L. Andres, C. Gonzalez, M. HeadGordon, E. S. Replogle, J. A. Pople, "Gaussian 98", Revision A.9, Gaussian, Inc., Pittsburgh 1998.

[25] M. R. Baklanov, K. P. Mogilnikov, V. G. Polovinkin, F. N. Dultsev, J. Vac. Sci. Technol. B 2000, 18, 1385.

[26] M. R. Baklanov, K. P. Mogilnikov, Microelectron. Eng. 2002, 64, 335.

[27] K. Maex, M. R. Baklanov, D. Shamiryan, F. Iacopi, S. Brongersma, Z. Sh. Yanovitskaya, J. Appl. Phys. 2003, 93, 8793.
[28] D. W. Gidley, W. E. Frieze, T. L. Dull, J. Sun, A. F. Yee, C. V. Nguyen, D. Y. Yoon, Appl. Phys. Lett. 2000, 76, 1282.

[29] D. W. Gidley, W. E. Frieze, A. F. Yee, T. L. Dull, H.-M. Ho, E. T. Ryan, Phys. Rev. B, Rapid Comm. 1999, 60, R5157.

[30] T. L. Dull, W. E. Frieze, D. W. Gidley, J. N. Sun, A. F. Yee, J. Phys. Chem. B. 2001, 105, 4657.

[31] W. C. Oliver, G. M. Pharr, J. Mater. Res. 1992, 7, 1564.

[32] J.-H. Yim, M. R. Baklanov, D. W. Gidley, H. Peng, H. D. Jeong, Y. S. Pu, J. Phys. Chem. B. 2004, 108, 8953.

[33] A. Jain, S. Rogojevic, W. N. Gill, J. L. Plawsky, I. Metthew, M. Tomojawa, E. Simonyi, J. Appl. Phys. 2001, 90, 5832 . 